\title{
Electrochemical Investigation on Adsorption of Fluconazole at Mild Steel/HCl Acid Interface as Corrosion Inhibitor
}

\author{
T. Jebakumar Immanuel Edison and M. G. Sethuraman \\ Department of Chemistry, Gandhigram Rural Institute, Deemed University, Dindigul District Gandhigram, \\ Tamil Nadu 624 302, India \\ Correspondence should be addressed to M. G. Sethuraman; mgsethu@gmail.com
}

Received 14 November 2012; Accepted 4 December 2012

Academic Editors: F. Deflorian and D. Losic

Copyright ( 2013 T. Jebakumar Immanuel Edison and M. G. Sethuraman. This is an open access article distributed under the Creative Commons Attribution License, which permits unrestricted use, distribution, and reproduction in any medium, provided the original work is properly cited.

\begin{abstract}
The interfacial behavior of fluconazole on mild steel in $1 \mathrm{M} \mathrm{HCl}$ solution was studied by electrochemical methods, namely, polarization (Tafel Plot) and Electrochemical Impedance Spectroscopy (EIS). The surface morphology of mild steel in the presence and absence of fluconazole was studied by Atomic Force Microscopy (AFM). The results of the study showed that fluconazole reduced the corrosion rate in $\mathrm{HCl}$ acid solution by adsorbing on the surface of mild steel. Tafel results suggest that fluconazole behaves predominantly as an anodic inhibitor and shows greater inhibition efficiency (96\%) at 0.30 mM. Thermodynamical parameters suggest that fluconazole is adsorbed on mild steel mainly by chemical mode. The EIS studies reveal the formation of a thin barrier film on mild steel surface. The AFM image of mild steel immersed in optimum concentration of fluconazole has confirmed the film formation on metal surface.
\end{abstract}

\section{Introduction}

Acid solutions are widely used in ore processing, fertilizer manufacturing, oil refining, waste water processing, chemical synthesis, and pickling and descaling processes [1-4]. Active metals such as mild steel, $\mathrm{Zn}$, and $\mathrm{Al}$ are employed in industries for fabrication purposes due to their easy availability and low cost, where surfaces are rapidly damaged in the presence of acids [5]. Among the various methods to control the destruction of these active metals in acid solutions, the use of inhibitors is quite popular [68]. Organic compounds containing heteroatoms like P, S, N, and $\mathrm{O}$ have been explored as good corrosion inhibitors [911]. They adsorb on the metal surface in the acid solutions either physically or chemically thereby blocking the corrosion reaction. However, most of these inhibitors suffer from nonbiodegradability and some of them are also toxic to living beings. In modern scenario, development of novel biodegradable and less toxic corrosion inhibitors is gaining importance. Biologically active molecules like sulfadimidine, sulfamethoxazole, cefatrexyl, apart from other antibacterial, and antifungal drugs have been reported as good corrosion inhibitors [12-18].
In the present study, adsorption behavior of an antifungal drug, fluconazole (2-(2,4-difluorophenyl)-1,3-di(1H1,2,4-triazol-1-yl)propan-2-ol), was evaluated for changes that occur in mild steel $/ \mathrm{HCl}$ acid interface in view of the fact that fluconazole contains two triazole rings with active centers like $\mathrm{N}$ and aromatic $\pi$ electrons, which can aid adsorption on mild steel surface minimizing the corrosion process in $\mathrm{HCl}$ medium.

Perusal of the literature shows that the adsorption behavior and kinetics of fluconazole were evaluated for $\mathrm{Al}$ in acid media $[19,20]$.

\section{Experimental Details}

2.1. Materials. Mild steel specimens of composition S-0.02$0.03 \%, \mathrm{P}-0.3-0.8 \%, \mathrm{Mn}-0.4-0.5 \%, \mathrm{C}-0.1-0.2 \%$, and the rest Fe with $1 \mathrm{~cm}^{2}$ exposed surface were used for the entire electrochemical studies.

Fluconazole received from IPCA laboratories Ltd, Mumbai, as a gift sample was used for the studies. AR grade $\mathrm{HCl}$ acid and double-distilled water were used for the entire study. The structure of the studied compound is given in Figure 1. 


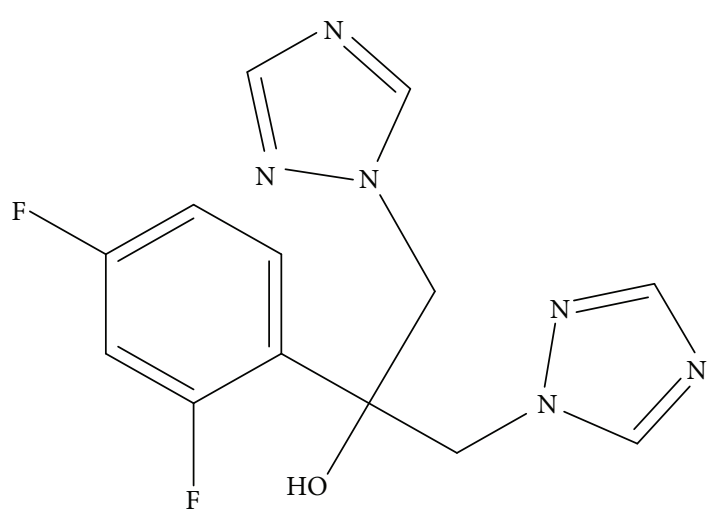

FIGURE 1: Structure of fluconazole.

2.2. Electrochemical Studies. All the electrochemical studies were carried out using $\mathrm{CH}$ Electrochemical analyzer model $760 \mathrm{D}$ with $\mathrm{CHI} 760 \mathrm{D}$ software. Conventional three-electrode system was used for polarization and EIS studies. In this setup, polished mild steel with $1 \mathrm{~cm}^{2}$ exposed surface area was used as working electrode, platinum electrode as an auxiliary electrode, and saturated calomel electrode as reference electrode. All the three electrodes were kept immersed in $1 \mathrm{M} \mathrm{HCl}$ both in the absence and presence of five different concentrations, namely, $0.03 \mathrm{mM}, 0.08 \mathrm{mM}, 0.16 \mathrm{mM}$, $0.24 \mathrm{mM}$, and $0.30 \mathrm{mM}$ of fluconazole. This setup was kept in room temperature for $30 \mathrm{~min}$ and then electrochemical measurements were carried out.

The open-circuit potential (OCP) versus time measurement was carried out for 60 secs. EIS measurements were carried out at corrosion potential $\left(E_{\text {corr }}\right)$ by changing the a.c frequency ranging from $0.1 \mathrm{~Hz}$ to $10000 \mathrm{~Hz}$ at $5 \mathrm{mV}$ of amplitude. Nyquist and Bode plots were obtained. From the Nyquist plots, charge transfer resistance $\left(R_{\mathrm{ct}}\right)$ and doublelayer capacitance $\left(C_{\mathrm{dl}}\right)$ of mild steel in presence and absence of fluconazole in $1 \mathrm{M} \mathrm{HCl}$ were computed. The simulation studies were carried out using $Z$ view software. The inhibition efficiency was calculated by using $R_{\mathrm{ct}}$ as in

$$
\operatorname{IE}(\%)=\left[\frac{R_{\mathrm{ct}(i)}-R_{\mathrm{ct}(b)}}{R_{\mathrm{ct}(i)}}\right] \times 100,
$$

where $R_{\mathrm{ct}(i)}$ is the charge transfer resistance of fluconazolecontained solution and $R_{\mathrm{ct}(b)}$ is the charge transfer resistance of the blank $\mathrm{HCl}$ solution.

The Tafel polarization curves were obtained by changing the electrode potential from $-150 \mathrm{mV}$ to $-750 \mathrm{mV}$ at opencircuit potential with a scan rate of $0.5 \mathrm{mV} \mathrm{s}^{-1}$. The linear Tafel segments of cathodic and anodic curves were extrapolated to corrosion potential to obtain the corrosion current densities $\left(i_{\text {corr }}\right)$. The inhibition efficiency was evaluated by using $i_{\text {corr }}$ values as given in

$$
\mathrm{IE}(\%)=\left[\frac{i_{\text {corr }}-i_{\text {corr }(1)}}{i_{\text {corr }}}\right] \times 100,
$$

where $i_{\text {corr }}$ is the corrosion current without fluconazole and $i_{\text {corr(1) }}$ is the corrosion current with fluconazole.

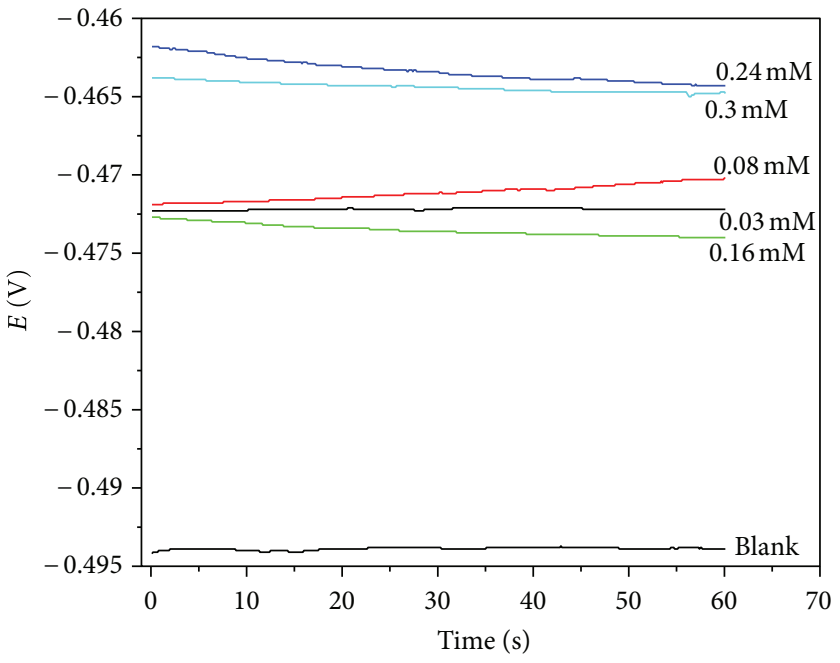

FIGURE 2: OCP response of mild steel with different concentrations of fluconazole in $1 \mathrm{M} \mathrm{HCl}$.

2.3. Surface Analysis. The AFM images of polished mild steel surface along with those immersed in $1 \mathrm{M} \mathrm{HCl}$ alone and $1 \mathrm{M}$ $\mathrm{HCl}$ with $0.3 \mathrm{mM}$ of fluconazole for 2 hours were scanned using Nano Surf Easy Scan 2 instrument at the range of $50 \mathrm{~mm}$.

\section{Results and Discussion}

3.1. OCP Studies. The OCP versus time plots for mild steel in blank acid and with different concentrations of fluconazole are shown in Figure 2. From the figures, the OCP of $1 \mathrm{M}$ $\mathrm{HCl}$ acid was found to be $-0.4939 \mathrm{~V}$. For an increase in concentration of inhibitor from $0.03 \mathrm{mM}$ to $0.30 \mathrm{mM}$, the OCP was shifted towards noble direction from -0.4722 to $-0.4644 \mathrm{~V}$, indicating that fluconazole controls mainly anodic metal dissolution reaction [21].

3.2. EIS Studies. Nyquist and Bode plots of mild steel in $1 \mathrm{M}$ $\mathrm{HCl}$ in the absence and presence of various concentrations of fluconazole are shown in Figures 3, 4, and 5. It is clear from these plots that the impedance of the mild steel substrate increases with the increase in the concentration of inhibitor in $1 \mathrm{M} \mathrm{HCl}$. It is worth noting that the change in the concentration of fluconazole did not alter the profile of the impedance behavior suggesting similar mechanism for the corrosion inhibition of mild steel by fluconazole at various concentrations.

The Nyquist and Bode plots display a single high frequency capacitive loop and a time constant, namely, solution resistance $\left(R_{s}\right)$ and charge transfer resistance $\left(R_{\mathrm{ct}}\right)$.

The corrosion process that occurs at the interface in fact has two steps. The first is the oxidation of the metal which is a charge transfer process and the second is the diffusion of the metallic ions from the metal surface to the solution which is a mass transfer process.

Shapes of the Nyquist plots show that the corrosion inhibition of fluconazole is only by charge transfer process 


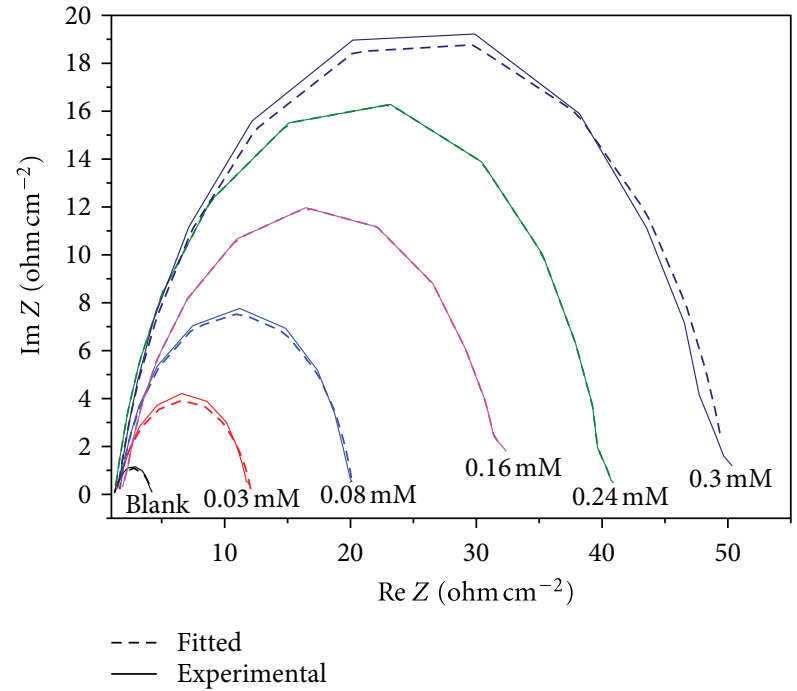

FIGURE 3: Nyquist plots of mild steel with different concentrations of fluconazole in $1 \mathrm{M} \mathrm{HCl}$ (Experimental and Fitted).

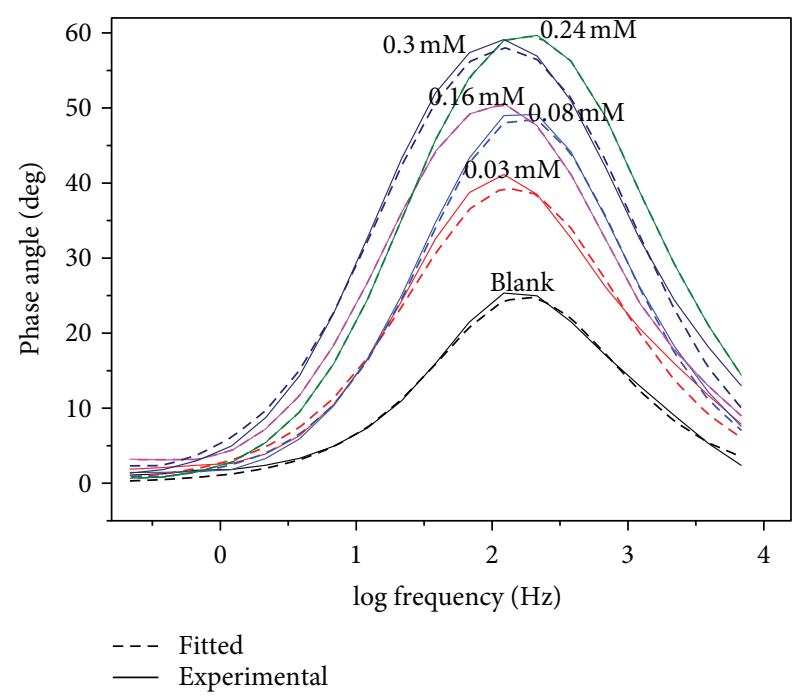

FIGURE 4: Frequency versus phase angle plots of mild steel with different concentrations of fluconazole in $1 \mathrm{M} \mathrm{HCl}$ acid (Bode).

[22]. The impedance behavior of mild steel with and without addition of fluconazole can be explained by the simplest model, namely, Randles circuit which includes the charge transfer resistance $\left(R_{\mathrm{ct}}\right)$ parallel with constant phase element (CPE) in series with solution resistance $\left(R_{s}\right)$ as represented in Figure 6. It can be noted from the Nyquist plots that the capacitive loops are depressed with center under the real axis even though they have a semicircular appearance. Deviations of this kind are often referred to as frequency dispersion [23] which is attributed to the irregularities and heterogeneities of the solid surface $[24,25]$. The imperfect semicircular Nyquist plot can be explained by the nonideal behavior of the double layer.

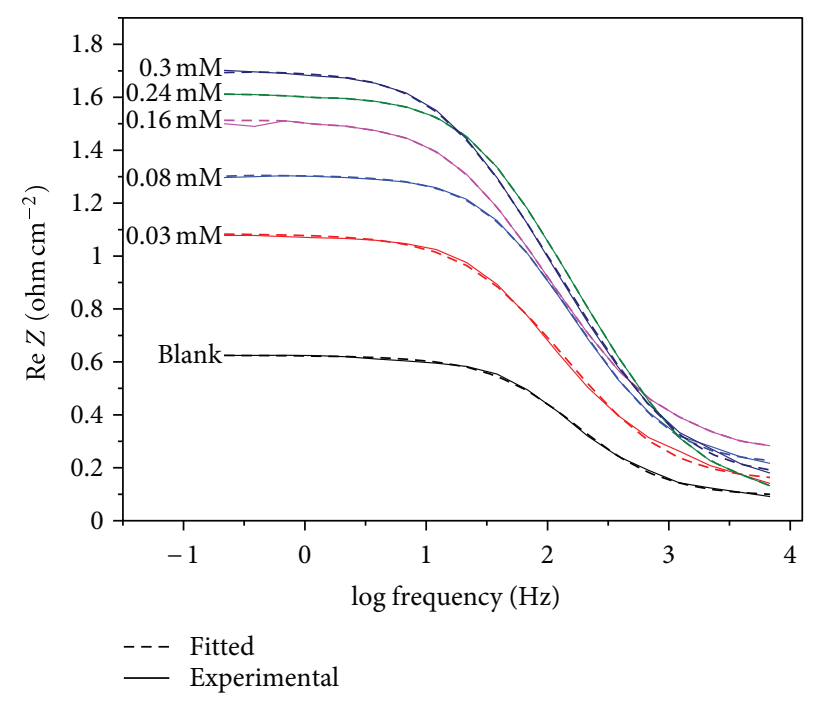

FIGURE 5: Frequency versus real resistance plots of mild steel with different concentrations of fluconazole in $1 \mathrm{M} \mathrm{HCl}$ acid (Bode).

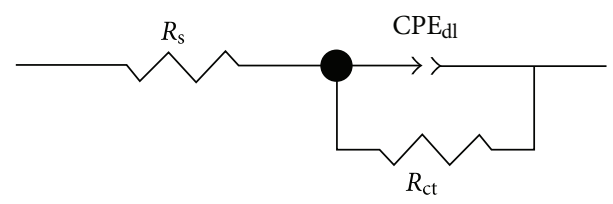

Figure 6: Equivalent circuit model for mild steel in $\mathrm{HCl}$ with and without fluconazole.

The impedance $(Z)$ of CPE is given by (3)

$$
Z_{\mathrm{CPE}}=\frac{1}{(i \omega)^{n} A},
$$

where $A$ is the proportionality coefficient, $\omega$ is the maximum frequency, $i^{2}=-1$ (imaginary number), and $n$ is the surface irregularity factor $(0 \leq n \leq 1)$.

Equivalent circuit of this type has been previously used to model the mild steel/acid interface. The replacement of $C_{\mathrm{dl}}$ with the $\mathrm{CPE}_{\mathrm{dl}}$ significantly improved the quality of the fit [26]. If the electrode surface is homogeneous (free from defects) and flat, the exponential value $(n)$ becomes equal to 1 and the metal solution interface acts as a capacitor with regular surface, that is, when $n=1 \mathrm{~A}=$ capacitance.

The lower value of $n$ for $1 \mathrm{M} \mathrm{HCl} \mathrm{(0.86)} \mathrm{indicated} \mathrm{the}$ surface inhomogeneity which resulted from roughening of metal surface due to corrosion. Upon addition of fluconazole, the $n$ value increased from 0.86 to $0.90(0.30 \mathrm{mM})$ indicating the reduction of surface defects due to adsorption of inhibitor at MS/acid solution interface [27].

The calculated impedance parameters are depicted in Table 1. Perusal of the table reveals that $R_{\mathrm{ct}}$ values increased with the increase in the concentration of fluconazole, which is due to the increased adsorption of the inhibitor at high concentration. Decrease of $\mathrm{CPE}_{\mathrm{dl}}$ may be caused by a reduction of local dielectric constant and/or by an increase in the thickness of the electrical double layer. These results very much suggest that fluconazole acts by adsorption at the 


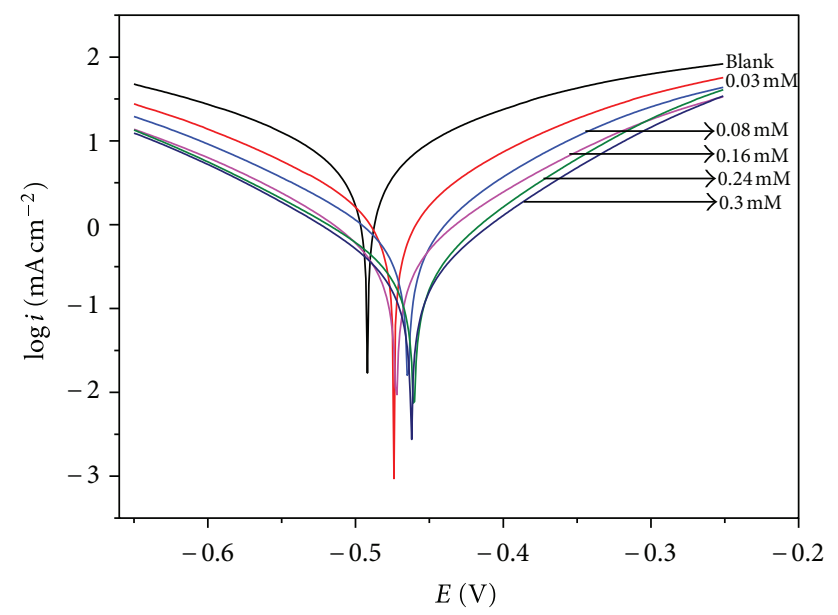

FIGURE 7: Tafel graphs of mild steel with different concentrations of fluconazole in $1 \mathrm{M} \mathrm{HCl}$.

metal/solution interface $[28,29]$. The addition of fluconazole decreases the $C P E_{\mathrm{dl}}$ values as a consequence to the replacement of water molecules by the inhibitor at the electrode surface.

3.3. Polarization Studies. Figure 7 depicts the cathodic and anodic polarization curves of mild steel in $1 \mathrm{M} \mathrm{HCl}$ at $303 \mathrm{~K}$ in the absence and presence of different concentrations of fluconazole and the potential versus current graphs are represented in Figure 8. The electrochemical parameters such as corrosion potential $\left(E_{\text {corr }}\right)$, cathodic and anodic Tafel slopes $\left(b_{c}\right.$ and $\left.b_{a}\right)$, corrosion current density $\left(i_{\text {corr }}\right)$, and polarization resistance $\left(R_{p}\right)$ were extracted from Figures 7 and 8 using CHI software and are shown in Table 2. From the results, it can be observed that the corrosion current decreases while increasing the concentration of fluconazole. The decrease of current density is due to the adsorption of inhibitor molecules on mild steel surface to retard the corrosion reaction of electrode with simultaneous replacement of electrolyte solutions at the interface [30]. Further, on increasing the inhibitor concentration, $E_{\text {corr }}$ values were shifted towards mainly positive side. This suggests that fluconazole behaves predominantly as an anodic inhibitor. The Tafel constants, namely, $b_{a}$ and $b_{c}$, decreased with the increasing of fluconazole concentration and $b_{a}$ was more deviated compared to $b_{c}$, showing that fluconazole controls mainly the anodic metal dissolution [31].

The polarization resistance $\left(R_{p}\right)$ increases with the increase of concentration of the inhibitor as well. The increasing of polarization resistance is mainly due to the adsorption of fluconazole on mild steel surface. Further, polarization resistances derived from Tafel plots (DC studies) and obtained from complex plane plots (sum of the $R_{s}$ and $R_{\mathrm{ct}}$ ) (AC studies) are in good agreement with each other $\left(R_{p}=R_{s}+R_{\mathrm{ct}}\right)$.

3.4. AFM Studies. AFM is a powerful tool to investigate the surface morphology and it is very useful to determine the film

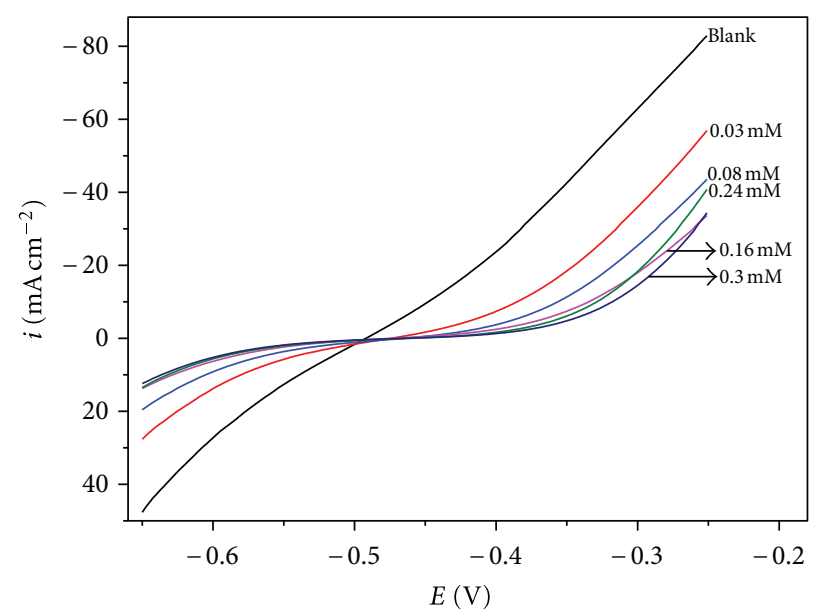

Figure 8: Potential versus Current response of mild steel with different concentrations of fluconazole in $1 \mathrm{M} \mathrm{HCl}$.

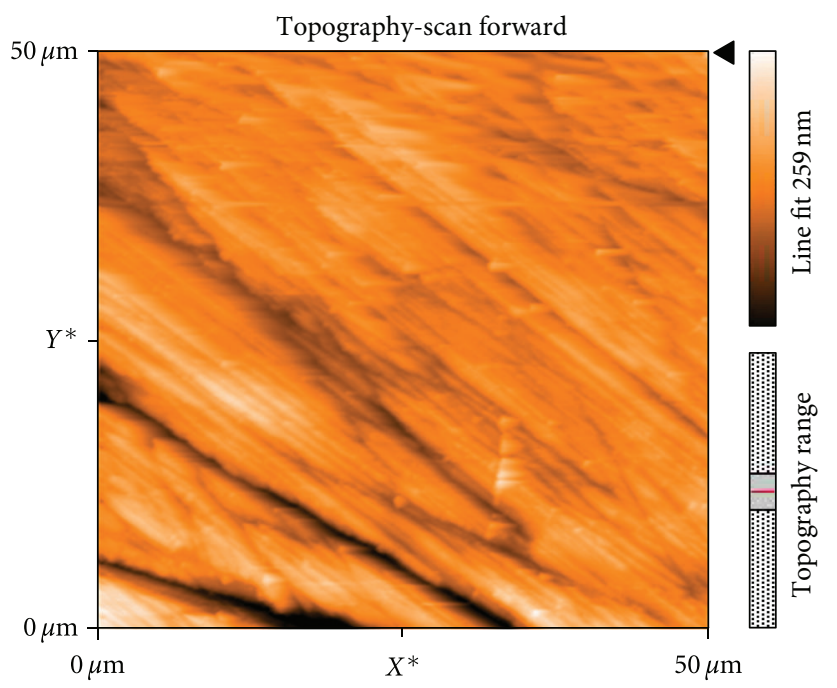

FIgURE 9: AFM image of polished mild steel surface.

formation on metal surface in corrosion inhibition studies. The AFM images of polished mild steel, mild steel in $1 \mathrm{M} \mathrm{HCl}$ with and without presence of $0.30 \mathrm{mM}$ fluconazole, are shown in Figures 9, 10, and 11. The AFM image of mild steel surface in $\mathrm{HCl}$ appears severely damaged than mild steel in $\mathrm{HCl}$ with $0.30 \mathrm{mM}$ of fluconazole. Moreover, the average roughness of polished mild steel and mild steel in blank $\mathrm{HCl}$ solution was calculated to be 82 and $450 \mathrm{~nm}$, respectively. With the addition of inhibitor, the average roughness was reduced to $208 \mathrm{~nm}$, which suggested the film formation of the inhibitor over the mild steel surface [32].

3.5. Adsorption Isotherms. Most of the corrosion inhibitors prevent metal dissolution by adsorption process (Badr, 2009). The \% IE of fluconazole was studied by Tafel and EIS methods which suggest that the surface coverage $(\theta=\mathrm{IE} \% / 100)$ increased with the increasing of inhibitor concentration. To describe the adsorption behavior of fluconazole, several 
TABLE 1: Electrochemical impedance parameters of mild steel in $1 \mathrm{M} \mathrm{HCl}$ in the absence and presence of different concentrations of fluconazole as extracted from Nyquist plots.

\begin{tabular}{lccccc}
\hline $\begin{array}{l}\text { Concentration } \\
\text { of inhibitor }(\mathrm{mM})\end{array}$ & $\begin{array}{c}R_{s} \\
\Omega \mathrm{cm}^{2}\end{array}$ & $\begin{array}{c}R_{\mathrm{ct}} \\
\Omega \mathrm{cm}^{2}\end{array}$ & $\begin{array}{c}\mathrm{CPE}_{\mathrm{dl}} \times 10^{-3} \\
\mathrm{~F} \mathrm{~cm}^{-2}\end{array}$ & $\begin{array}{c}\mathrm{CPE}_{p} \\
(n)\end{array}$ \\
\hline Blank & 1.2300 & 2.988 & 2.0683 & 0.80437 & - \\
0.03 & 1.3960 & 10.7600 & 1.1944 & 0.8115 \\
0.08 & 1.63 & 18.61 & 0.4375 & 0.8202 \\
0.16 & 1.863 & 31.02 & 0.6146 & 0.8422 \\
0.24 & 1.273 & 39.49 & 0.3113 & 0.8686 \\
0.30 & 1.463 & 48.68 & 0.42846 & 0.8765 & 90.37 \\
\hline
\end{tabular}

TABLE 2: Tafel polarization parameters for mild steel in $1 \mathrm{M} \mathrm{HCl}$ in the absence and presence of different concentrations of fluconazole.

\begin{tabular}{lcccccc}
\hline $\begin{array}{l}\text { Concentration } \\
\text { of inhibitor }(\mathrm{mM})\end{array}$ & $\begin{array}{c}-b_{a} \\
\mathrm{~V} \mathrm{dec}^{-1}\end{array}$ & $\begin{array}{c}-b_{c} \\
\mathrm{~V} \mathrm{dec}^{-1}\end{array}$ & $\begin{array}{c}E_{\text {corr }} \\
\mathrm{V}\end{array}$ & $\begin{array}{c}i_{\text {corr }} \times 10^{-3} \\
\left(\mathrm{~A} \mathrm{~cm}^{-2}\right)\end{array}$ & $\begin{array}{c}R_{p} \\
\Omega / \mathrm{cm}^{2}\end{array}$ & $\begin{array}{c}\text { Average } \\
\text { OCP }(\mathrm{V})\end{array}$ \\
\hline Blank & 0.1498 & 0.1596 & -0.492 & 7.052 & 5 & -0.4939 \\
0.03 & 0.1043 & 0.1241 & -0.474 & 1.575 & 16 & -0.4722 \\
0.08 & 0.0882 & 0.1164 & -0.465 & 0.7353 & 30 & -0.4712 \\
0.16 & 0.1002 & 0.1109 & -0.472 & 0.4803 & 48 & -0.4735 \\
0.24 & 0.0823 & 0.1067 & -0.461 & 0.3096 & 65 & -0.4633 \\
0.30 & 0.0874 & 0.1029 & -0.462 & 0.2595 & 79 & 95.61 \\
\hline
\end{tabular}

adsorption isotherms have been tested and the Langmuir kinetic thermodynamic model fits the experimental data well.

Langmuir isotherm is given by [33] the following:

$$
\begin{gathered}
\ln \frac{\theta}{1-\theta}=\ln K+\ln C, \\
K=\frac{1}{55.5} \exp \left(-\frac{\Delta G_{\mathrm{ads}}}{\mathrm{RT}}\right),
\end{gathered}
$$

where $\theta$-degree is the surface coverage, $C$ is the molar inhibitor concentration, and $K$ is the equilibrium constant of the adsorption process.

The Langmuir isotherm assumes the adsorption of organic molecules as a monolayer over the metallic surface without any interactions with other molecules adsorbed [34]. By using this isotherm, the free energy of adsorption $\left(\Delta G_{\text {ads }}\right)$ was calculated by plotting $\ln C(\mathrm{M})$ versus $\ln \theta /(1-\theta)$. The value of adsorption equilibrium constant is calculated from the intercept of the straight line obtained from Figures 12 and 13. As shown in the results (Table 3), negative sign of $\Delta G_{\text {ads }}$ indicates that the adsorption process of fluconazole over mild steel occurs spontaneously. The values of $\Delta G_{\text {ads }}$ calculated by Tafel and impedance methods are -35.39 and $-32.01 \mathrm{~kJ} \mathrm{~mol}^{-1}$, respectively. These values are at the interval of physical adsorption and chemical binding and indicate chemical adsorption of the inhibitor [35].

The adsorption process depends upon the size, orientation, shape, and electric charge of the inhibitor in addition to the charge on the metal surface [36]. The chemisorption involves electron sharing between metal surface and the inhibitor, whereas physisorption may occur due to the interaction between the charged metal surface and protonated inhibitor. Polarization studies reveal that fluconazole
TABLE 3: Thermodynamic parameters derived from Langmuir isotherm for adsorption of fluconazole on mild steel in $1 \mathrm{M} \mathrm{HCl}$ at $298 \mathrm{~K}$.

\begin{tabular}{lccc}
\hline Method & $\begin{array}{c}\text { Equilibrium constant } \\
(K) \mathrm{M}^{-1}\end{array}$ & $R^{2}$ & $\begin{array}{c}\text { Free energy of adsorption } \\
\left(\Delta G_{\mathrm{ads}}\right) \mathrm{kJ} \mathrm{mol}^{-1}\end{array}$ \\
\hline Tafel & 28853.89 & 0.995 & -35.39 \\
EIS & 7346.65 & 0.997 & -32.01 \\
\hline
\end{tabular}

predominantly controls the anodic dissolution reaction. The chemisorptive bonds could be formed due to the sharing of electron pair between metal and unprotonated hetero atoms of fluconazole. Further, it is also possible that there could be an interaction between the electrons of $\pi$ orbitals of fluconazole with metal surface [37].

\section{Conclusion}

From the studies, the following are concluded.

(i) Fluconazole behaves good corrosion inhibitor for mild steel in $\mathrm{HCl}$ medium.

(ii) The results of polarization studies reveal that fluconazole acts as a predominantly anodic inhibitor and controls the metal dissolution.

(iii) The results of EIS studies confirm the formation of barrier layer by fluconazole on mild steel surface and further the charge transfer process controls the corrosion.

(iv) The AFM images as well as the values of average surface roughness support the formation of barrier film. 


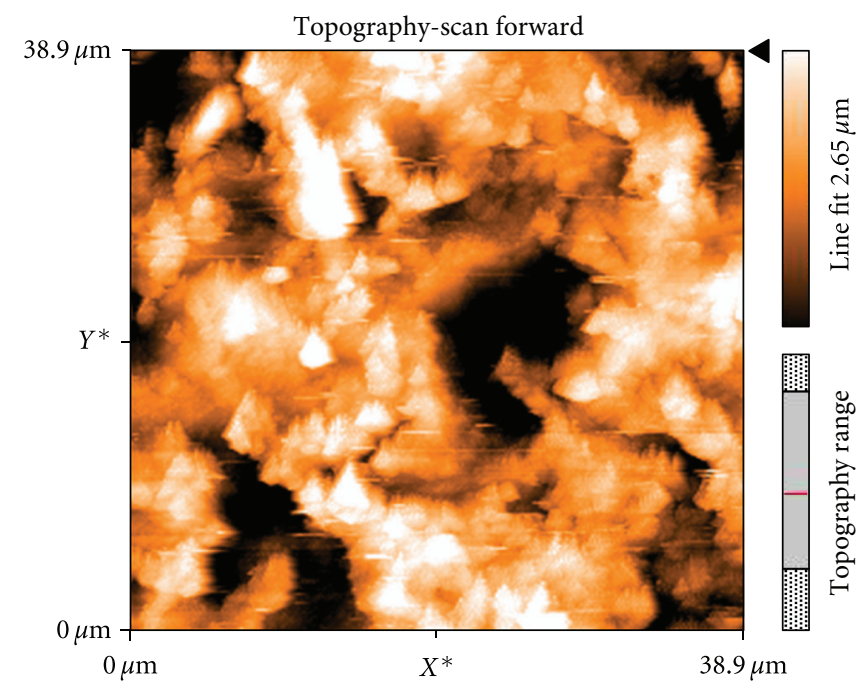

FIGURE 10: AFM image of mild steel in $1 \mathrm{M} \mathrm{HCl}$.

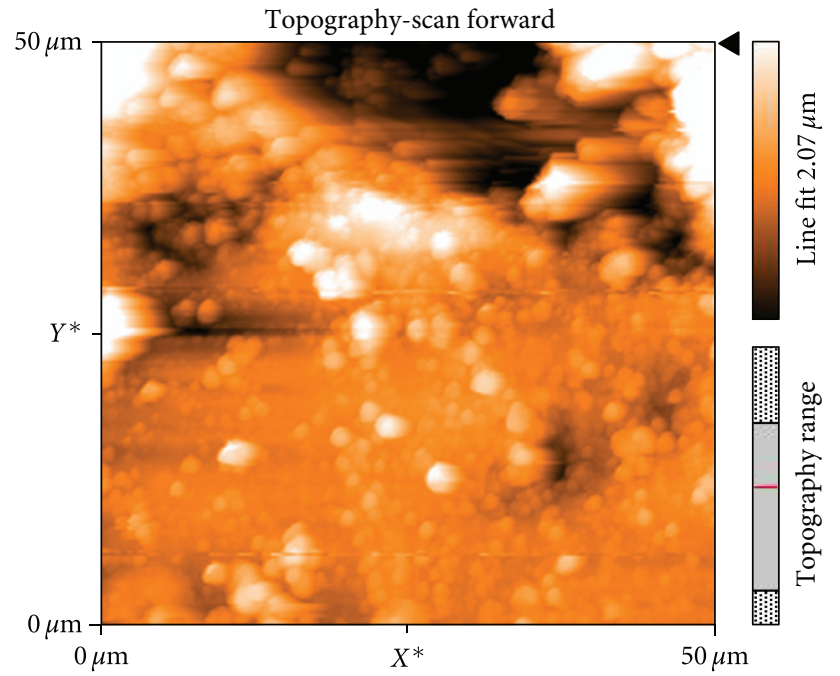

FIGURE 11: AFM image of mild steel in $1 \mathrm{M} \mathrm{HCl}$ with $0.30 \mathrm{mM}$ of fluconazole.

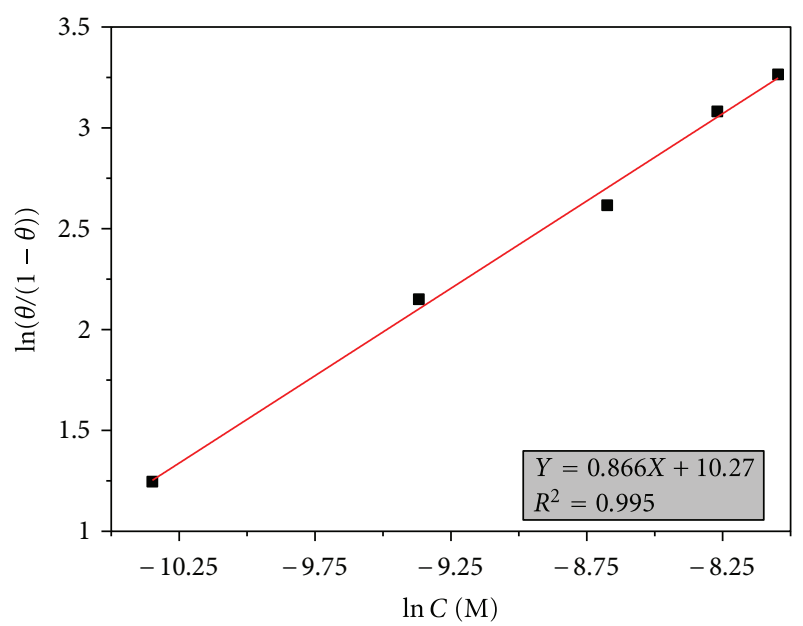

FIGURE 12: Langmuir adsorption isotherm plot (using Tafel results) for the adsorption of fluconazole on mild steel in $1 \mathrm{M} \mathrm{HCl}$.

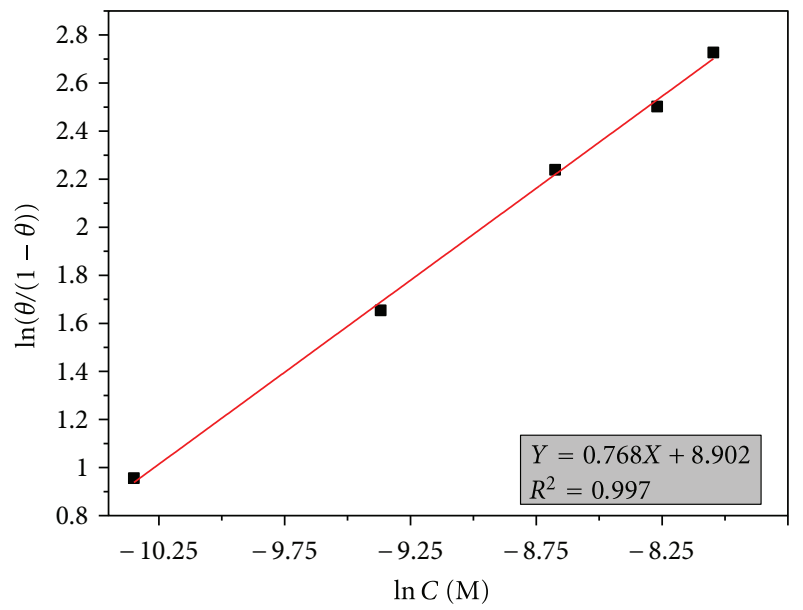

FIGURE 13: Langmuir adsorption isotherm plot (using EIS results) for the adsorption of fluconazole on mild steel in $1 \mathrm{M} \mathrm{HCl}$.

(v) The corrosion inhibition of fluconazole can be attributed mainly due to chemisorption at mild steel/HCl acid interface as supported by the results of isotherm studies.

\section{Acknowledgments}

The authors wish to thank UGC, New Delhi, for financial assistance through Special Assistance Grant. The authors also thank IPCA laboratories Ltd, Mumbai, for the gift sample of fluconazole.

\section{References}

[1] C. Kamal and M. G. Sethuraman, "Caulerpin-A bis-Indole alkaloid as a green inhibitor for the corrosion of mild steel in $1 \mathrm{M} \mathrm{HCl}$ solution from the marine Alga Caulerpa racemosa," Industrial \& Engineering Chemistry Research, vol. 51, pp. 10399-10407, 2012. 
[2] S. Faraji, A. A. Rahim, N. Mohamed, C. S. Sipaut, and B. Raja, "The influence of $\mathrm{SiC}$ particles on the corrosion resistance of electroless, Cu-P composite coating in $1 \mathrm{M} \mathrm{HCl,"} \mathrm{Materials}$ Chemistry and Physics, vol. 129, no. 3, pp. 1063-1070, 2011.

[3] O. Benali, L. Larabi, and Y. Harek, "Inhibiting effects of 2mercapto-1-methylimidazole on copper corrosion in $0.5 \mathrm{M}$ sulfuric acid," Journal of Saudi Chemical Society, vol. 14, no. 2, pp. 231-235, 2010.

[4] L. Afia, R. Salghi, L. Bammou et al., "Anti-corrosive properties of Argan oil on C38 steel in molar HCl solution," Journal of Saudi Chemical Society. In press.

[5] A. N. Senthilkumar, K. Tharini, and M. G. Sethuraman, "Corrosion inhibitory effect of few piperidin-4-one oximes on mild steel in hydrochloric acid medium," Surface Review and Letters, vol. 16, no. 1, pp. 141-147, 2009.

[6] A. A. Al-Sarawy, A. S. Fouda, and W. A. S. El-Dein, "Some thiazole derivatives as corrosion inhibitors for carbon steel in acidic medium," Desalination, vol. 229, no. 1-3, pp. 279-293, 2008.

[7] B. Hammouti, A. Dafali, R. Touzani, and M. Bouachrine, "Inhibition of copper corrosion by bipyrazole compound in aerated 3\% NaCl," Journal of Saudi Chemical Society, vol. 16, no. 4, pp. 413-418, 2011.

[8] M. S. Al-Otaibi, A. M. Al-Mayouf, M. Khan, A. A. Mousa, S. A. Al-Mazroa, and H. Z. Alkhathlan, "Corrosion inhibitory action of some plant extracts on the corrosion of mild steel in acidic media," Arabian Journal of Chemistry. In press.

[9] C. Kamal and M. G. Sethuraman, "Spirulina platensis: a novel green inhibitor for acid corrosion of mild steel," Arabian Journal of Chemistry, vol. 5, no. 2, pp. 155-161, 2012.

[10] K. F. Khaled, "Monte Carlo simulations of corrosion inhibition of mild steel in $0.5 \mathrm{M}$ sulphuric acid by some green corrosion inhibitors," Journal of Solid State Electrochemistry, vol. 13, no. 11, pp. 1743-1756, 2009.

[11] I. B. Obot, N. O. Obi-Egbedi, and A. O. Eseola, "Anticorrosion potential of 2-mesityl-1H-imidazo[4,5-f][1,10]phenanthroline on mild steel in sulfuric acid solution: experimental and theoretical study," Industrial and Engineering Chemistry Research, vol. 50, no. 4, pp. 2098-2110, 2011.

[12] A. N. Senthilkumar and M. G. Sethuraman, "Corrosion inhibition potential of sulfadimidine," Corrosion Reviews, vol. 26, no. 1, pp. 23-37, 2008.

[13] M. M. El-Naggar, "Corrosion inhibition of mild steel in acidic medium by some sulfa drugs compounds," Corrosion Science, vol. 49, no. 5, pp. 2226-2236, 2007.

[14] M. S. Morad, "Inhibition of iron corrosion in acid solutions by Cefatrexyl: behaviour near and at the corrosion potential," Corrosion Science, vol. 50, no. 2, pp. 436-448, 2008.

[15] M. Abdallah, "Antibacterial drugs as corrosion inhibitors for corrosion of aluminium in hydrochloric solution," Corrosion Science, vol. 46, no. 8, pp. 1981-1996, 2004.

[16] A. S. Fouda, H. A. Mostafa, and H. M. El-Abbasy, "Antibacterial drugs as inhibitors for the corrosion of stainless steel type 304 in $\mathrm{HCl}$ solution," Journal of Applied Electrochemistry, vol. 40, no. 1, pp. 163-173, 2010.

[17] I. B. Obot, N. O. Obi-Egbedi, and S. A. Umoren, "Adsorption characteristics and corrosion inhibitive properties of clotrimazole for aluminium corrosion in hydrochloric acid," International Journal of Electrochemical Science, vol. 4, no. 6, pp. 863-877, 2009.
[18] M. Abdallah, "Rhodanine azosulpha drugs as corrosion inhibitors for corrosion of 304 stainless steel in hydrochloric acid solution," Corrosion Science, vol. 44, no. 4, pp. 717-728, 2002.

[19] I. B. Obot, N. O. Obi-Egbedi, and S. A. Umoren, "Antifungal drugs as corrosion inhibitors for aluminium in $0.1 \mathrm{M} \mathrm{HCl}$," Corrosion Science, vol. 51, no. 8, pp. 1868-1875, 2009.

[20] I. B. Obot and N. O. Obi-Egbedi, "Fluconazole as an inhibitor for aluminium corrosion in $0.1 \mathrm{M} \mathrm{HCl,"} \mathrm{Colloids} \mathrm{and} \mathrm{Surfaces}$ A, vol. 330, no. 2-3, pp. 207-212, 2008.

[21] D. Gopi and S. Rajeswari, "Surface characterization and electrochemical corrosion behaviour of 304 stainless steel in aqueous media," Journal of Solid State Electrochemistry, vol. 6, no. 3, pp. 194-202, 2002.

[22] A. S. Patel, V. A. Panchal, G. V. Mudaliar, and N. K. Shah, "Impedance spectroscopic study of corrosion inhibition of AlPure by organic Schiff base in hydrochloric acid," Journal of Saudi Chemical Society. In press.

[23] A. M. Al-Turkustani, S. T. Arab, and L. S. S. Al-Qarni, "Medicago Sative plant as safe inhibitor on the corrosion of steel in $2.0 \mathrm{M} \mathrm{H}_{2} \mathrm{SO}_{4}$ solution," Journal of Saudi Chemical Society, vol. 15 , no. 1, pp. 73-82, 2011.

[24] C. Kamal and M. G. Sethuraman, "Hydroclathrus clathratus: a marine alga used as green inhibitor for acid corrosion of mild steel," Research on Chemical Intermediates. In press.

[25] E. Naderi, A. H. Jafari, M. Ehteshamzadeh, and M. G. Hosseini, "Effect of carbon steel microstructures and molecular structure of two new Schiff base compounds on inhibition performance in $1 \mathrm{M} \mathrm{HCl}$ solution by EIS," Materials Chemistry and Physics, vol. 115, no. 2-3, pp. 852-858, 2009.

[26] A. Popova, E. Sokolova, S. Raicheva, and M. Christov, "AC and DC study of the temperature effect on mild steel corrosion in acid media in the presence of benzimidazole derivatives," Corrosion Science, vol. 45, no. 1, pp. 33-58, 2003.

[27] A. K. Satapathy, G. Gunasekaran, S. C. Sahoo, K. Amit, and P. V. Rodrigues, "Corrosion inhibition by Justicia gendarussa plant extract in hydrochloric acid solution," Corrosion Science, vol. 51, no. 12, pp. 2848-2856, 2009.

[28] M. A. Hegazy, "A novel Schiff base-based cationic gemini surfactants: synthesis and effect on corrosion inhibition of carbon steel in hydrochloric acid solution," Corrosion Science, vol. 51, no. 11, pp. 2610-2618, 2009.

[29] R. Touir, N. Dkhireche, M. E. Touhami, M. E. Bakri, A. H. Rochdi, and R. A. Belakhmima, "Study of the mechanism action of sodium gluconate used for the protection of scale and corrosion in cooling water system," Journal of Saudi Chemical Society. In press.

[30] K. Stanly Jacob and G. Parameswaran, "Corrosion inhibition of mild steel in hydrochloric acid solution by Schiff base furoin thiosemicarbazone," Corrosion Science, vol. 52, no. 1, pp. 224-228, 2010.

[31] S. V. Ramesh and A. V. Adhikari, "N' -[4-(diethylamino)benzylidine $]-3-\{[8$-(trifluoromethyl) quinolin-4-yl]thio\}propano hydrazide) as an effective inhibitor of mild steel corrosion in acid media," Materials Chemistry and Physics, vol. 115, no. 2-3, pp. 618-627, 2009.

[32] A. K. Singh and M. A. Quraishi, "Effect of Cefazolin on the corrosion of mild steel in $\mathrm{HCl}$ solution," Corrosion Science, vol. 52, no. 1, pp. 152-160, 2010. 
[33] P. Lowmunkhong, D. Ungthararak, and P. Sutthivaiyakit, "Tryptamine as a corrosion inhibitor of mild steel in hydrochloric acid solution," Corrosion Science, vol. 52, no. 1, pp. 30-36, 2010.

[34] M. Abdeli, N. P. Ahmadi, and R. A. Khosroshahi, "Influence of bis-(2-benzothiazolyl)-disulfide on corrosion inhibition of mild steel in hydrochloric acid media," Journal of Solid State Electrochemistry, vol. 15, no. 9, pp. 1867-1873, 2011.

[35] M. Abdeli, N. P. Ahmadi, and R. A. Khosroshahi, "Nile Blue and Indigo Carmine organic dyes as corrosion inhibitor of mild steel in hydrochloric acid," Journal of Solid State Electrochemistry, vol. 14, no. 7, pp. 1317-1324, 2010.

[36] I. Ahamad, R. Prasad, and M. A. Quraishi, "Experimental and theoretical investigations of adsorption of fexofenadine at mild steel/hydrochloric acid interface as corrosion inhibitor," Journal of Solid State Electrochemistry, vol. 14, no. 11, pp. 2095-2105, 2010.

[37] M. A. Quraishi, A. Singh, V. K. Singh, D. K. Yadav, and A. K. Singh, "Green approach to corrosion inhibition of mild steel in hydrochloric acid and sulphuric acid solutions by the extract of Murraya koenigii leaves," Materials Chemistry and Physics, vol. 122, no. 1, pp. 114-122, 2010. 


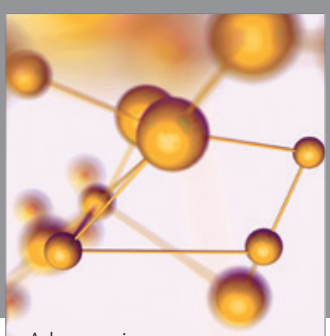

Physical Chemistry
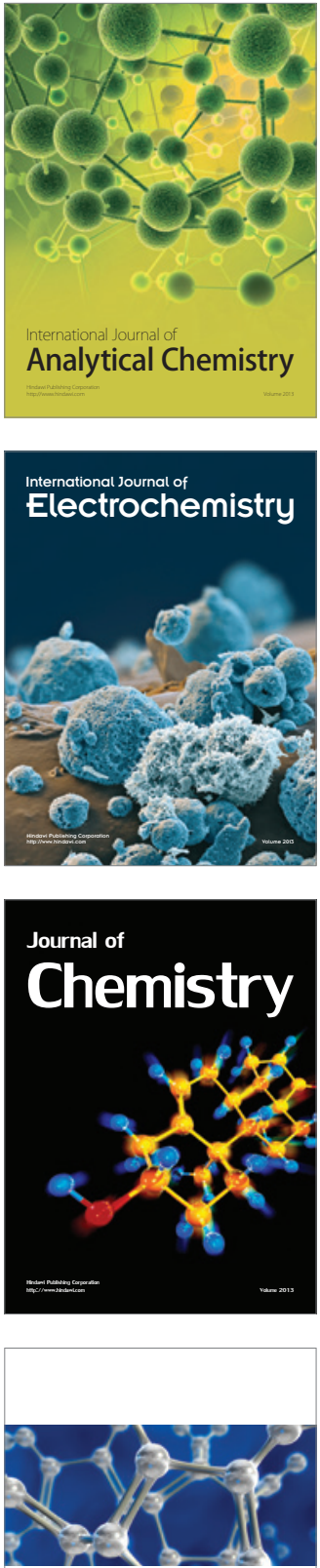

ISRN

Inorganic Chemistry

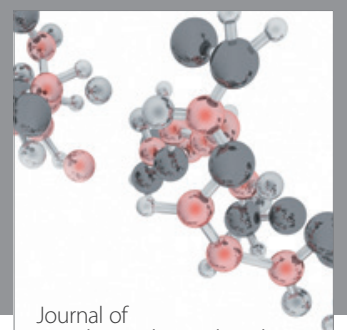

Analytical Methods in Chemistry

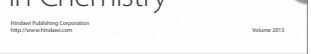

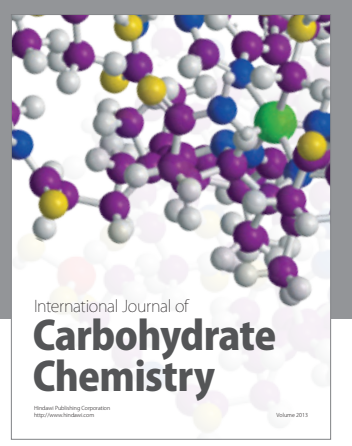
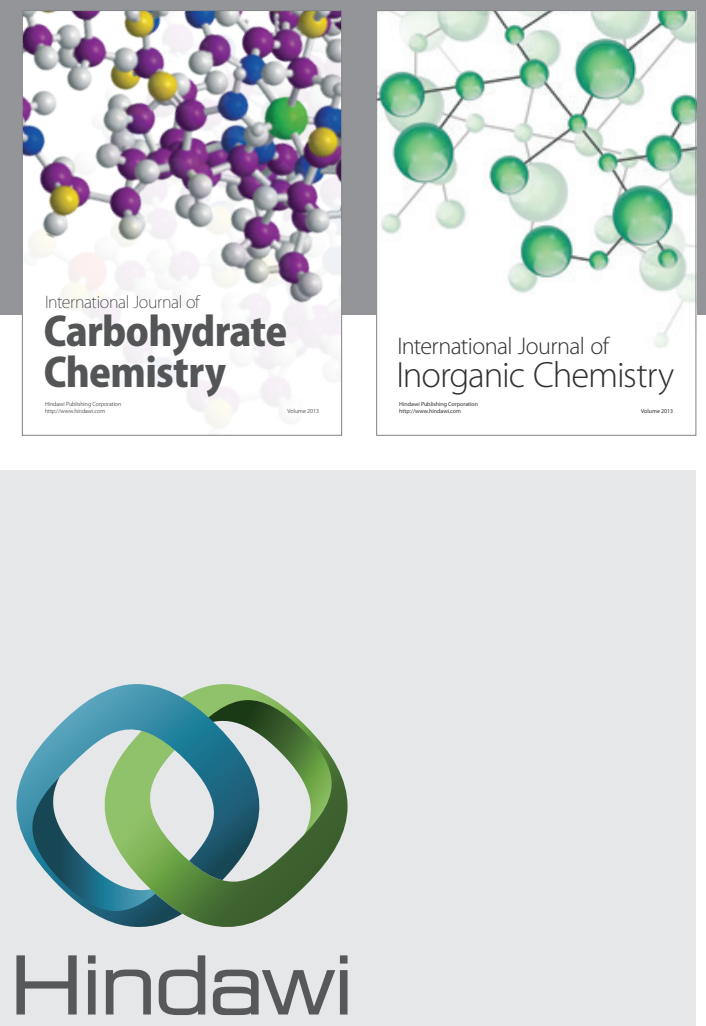

Submit your manuscripts at http://www.hindawi.com
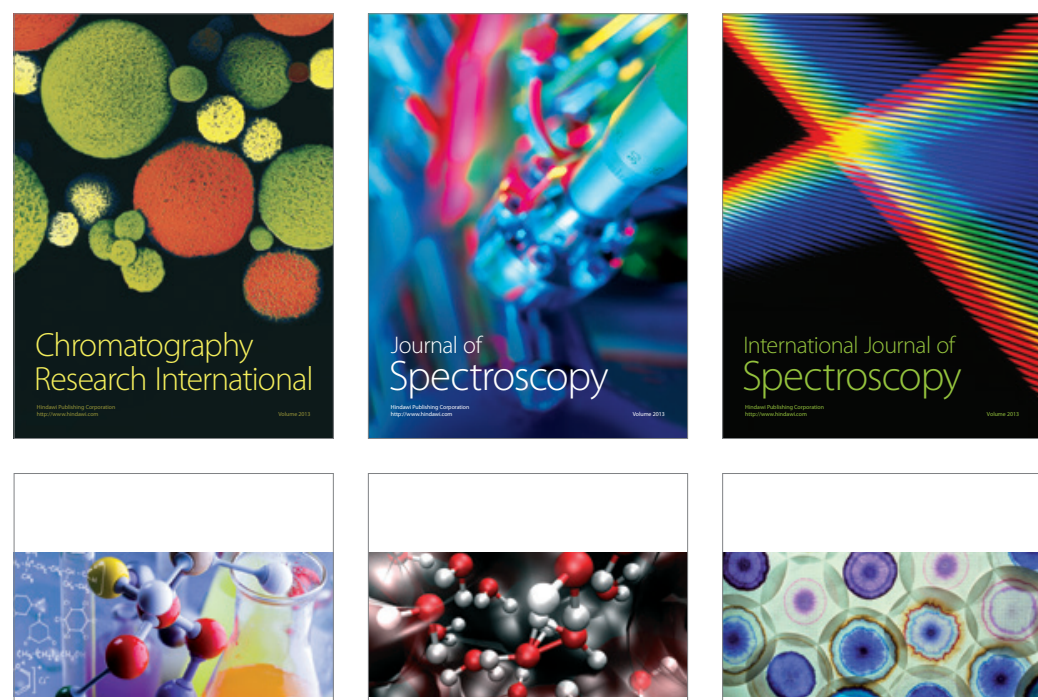

ISRN

ISRN

Organic Chemistry

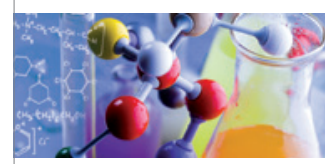

Physical Chemistry

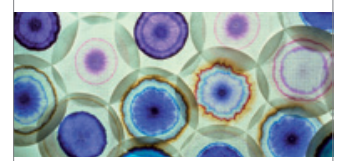

ISRN

Chromatography

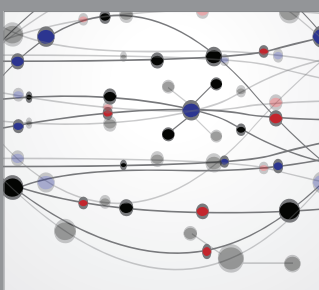

The Scientific World Journal
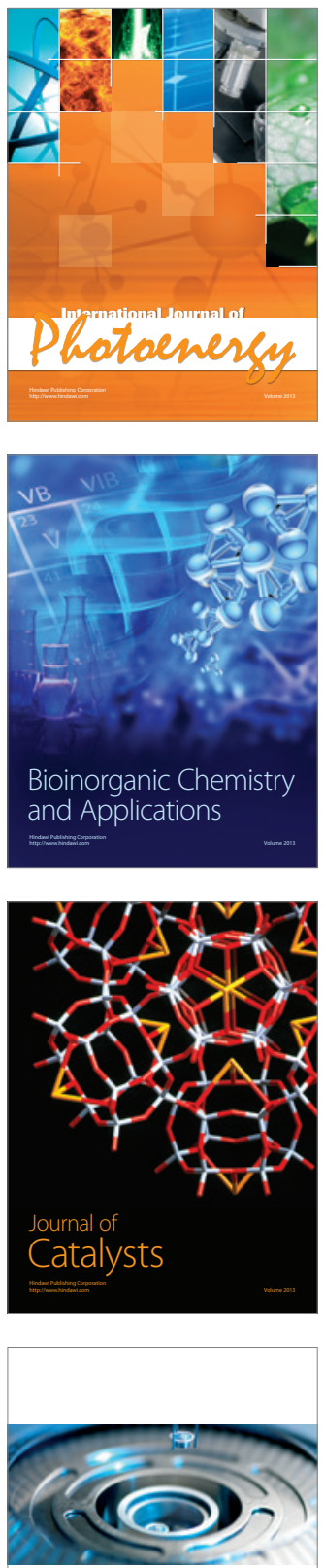

ISRN

Analytical

Chemistry 


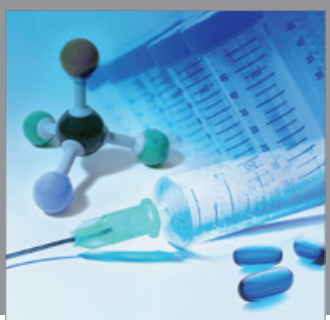

International Journal of

Medicinal Chemistry

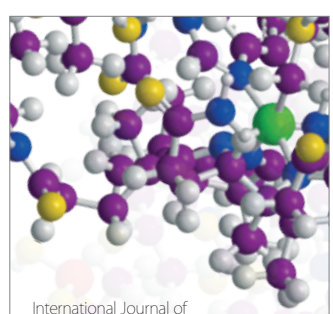

Carbohydrate Chemistry

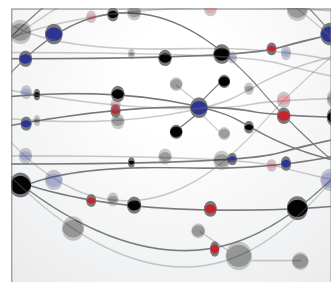

The Scientific World Journal
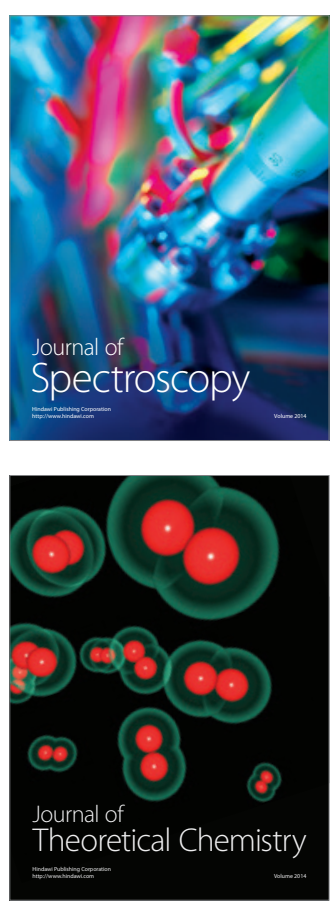
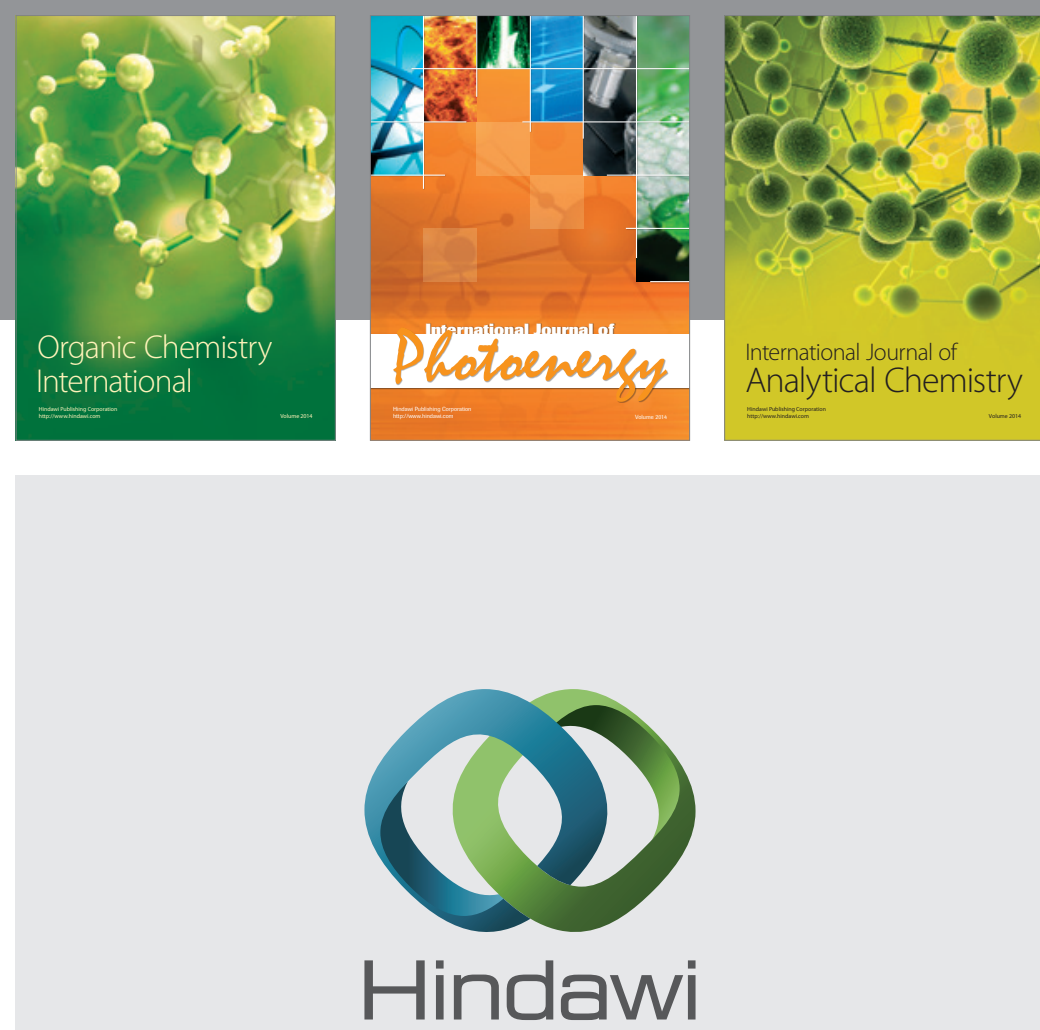

Submit your manuscripts at

http://www.hindawi.com
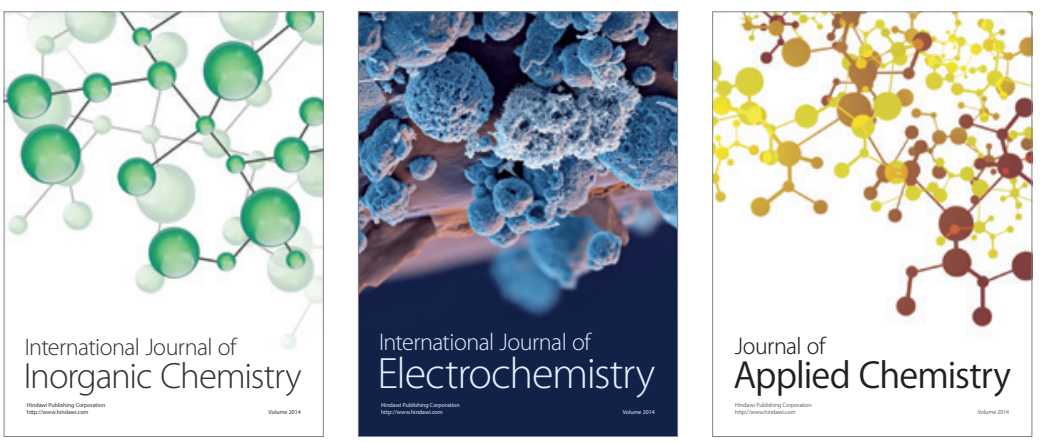

Journal of

Applied Chemistry
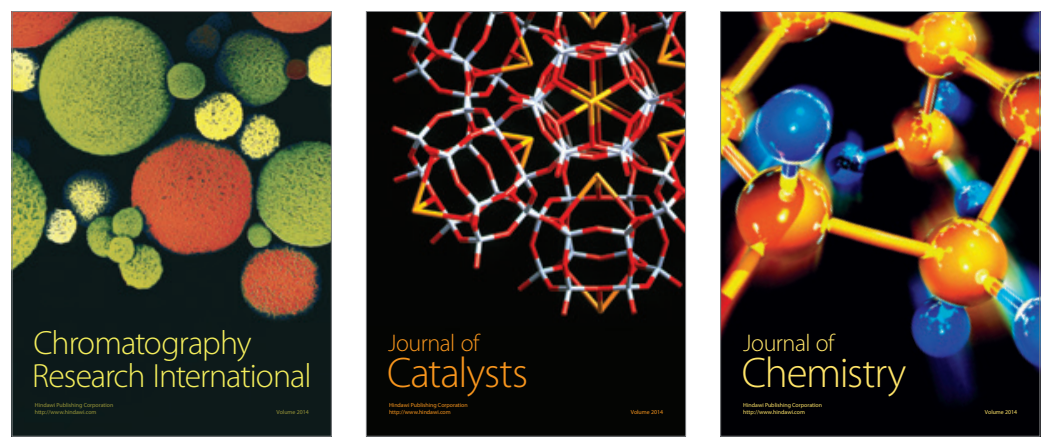
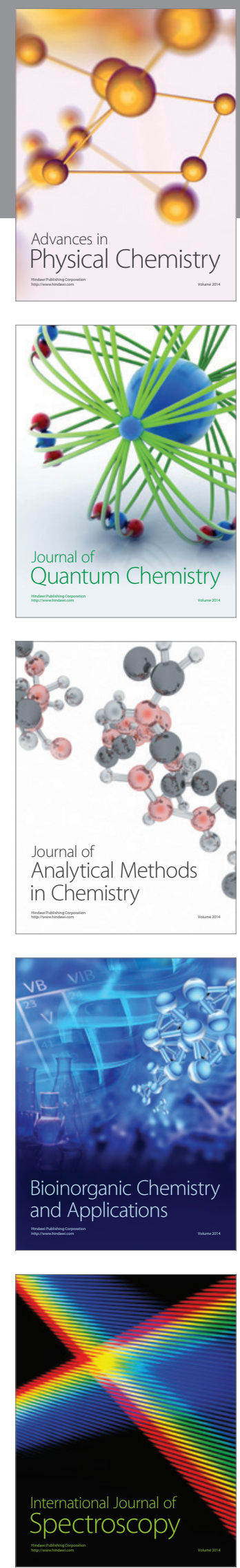